\title{
Prospects for the use of vitamin $\mathrm{D}_{3}$
}

\author{
Bouzid Djihane $^{\mathrm{a}}$,Merzouki Samir ${ }^{\mathrm{b}}$, and Zerroug Mohamed Mihoub ${ }^{\mathrm{a}}$ \\ ${ }^{a}$ Laboratory of Applied Microbiology, Faculty of Nature and Life Sciences, University Ferhat \\ Abbas Sétif 1, Sétif, Algeria \\ ${ }^{b}$ Laboratory Bouchara Recordati, Alpha Consult, Algeria..
}

\section{Summary}

Pathogenic fungi are now a real problem in several areas, especially the medical and food field due to their powers of contamination and pathogenicity, as well as the resistance to the majority of antifungals drugs that are most of the time fungistatic. So it is necessary to find new powerful and effective antifungals drugs with a fungicidal action on these pathogens. Vitamin $\mathrm{D}_{3}$ were selected for the test of antifungal activity, through its spectrum of biological activity, so the purpose of our study is to prove that vitamin $\mathrm{D}_{3}$ has a powerful fungicide effect towards the identified fungal strains after isolated from different source (plants, soil, bread... etc).

The test of antifungal activity shows that vitamin $\mathrm{D}_{3}$ has a powerful effect on the majority of the strains tested at a minimum fungicide concentration $\mathrm{MFC}_{\mathrm{C}}=100 \mu \mathrm{g} / \mathrm{ml}$ and the inhibition zones vary between 9.33 and $25.5 \mathrm{~mm}$ including $6 \mathrm{~mm}$ the diameter of disc.

The obtained minimum fungistatic concentration $\mathrm{MFC}_{\mathrm{S}}$ are between 50 and $12.5 \mu \mathrm{g} . \mathrm{ml}^{-1}$, and the value of vitamin $\mathrm{D}_{3} \mathrm{MFC} \mathrm{C}_{\mathrm{C}}$ is between 50 and $100 \mu \mathrm{g} \cdot \mathrm{ml}^{-1}$. The $\mathrm{MFC}_{\mathrm{C}} / \mathrm{MFC}_{\mathrm{S}}=2<4$ so vitamin $\mathrm{D}_{3}$ shows a fungicidal effect.

So the Vitamin $\mathrm{D}_{3}$ can be proposed as a medical treatment against human pathogenic fungi or natural food preservative in the field of food industry.

Key words: Vitamin $D_{3}$, antifungal activity, fungicidal, fungistatic, minimum fungicidal concentration $\mathrm{MFC}_{\mathrm{C}}$, minimum fungistatic concentration $\mathrm{MFC}_{\mathrm{S}}$ 
